Pacific Journal of Mathematic 


\section{A NEW APPROACH TO REPRESENTATION THEORY FOR CONVOLUTION TRANSFORMS}

\section{Leviatan}

There are two different ways by which one obtains representation theorems for the Laplace transform. One way is to impose integral conditions on the inverse operator; and the other way is to impose summation conditions without referring to the inverse operator. Representation theorems for the convolution transform have hitherto been obtained by imposing integral conditions on the inverse operator, and no attempt has been made to impose summation conditions. We obtain here some representation theorems, which involve summation conditions, for convolution transforms with kernels in Class II. A representation theorem for convolution transforms of Class II with determining functions of bounded variation in $(-\infty, \infty)$, is given. Also, representation theorems involving determining functions which are integrals of functions in the Orlicz class $L_{M}(-\infty, \infty)$ are obtained.

In the sequel we follow the notation of Hirschman and Widder [2].

2. Notation and an auxiliary lemma. Let the sequence $\left\{a_{n}\right\}$ $(n \geqq 1)$ satisfy

$$
0<a_{1} \leqq a_{2} \leqq \cdots \leqq a_{n} \leqq \cdots ; \sum_{n=1}^{\infty} \frac{1}{a_{n}}=\infty ; \sum_{n=1}^{\infty} \frac{1}{a_{n}^{2}}<\infty .
$$

Set

$$
E(s)=\prod_{k=1}^{\infty}\left(1-\frac{s}{a_{k}}\right) e^{s / a_{k}}
$$

where $s$ is complex and where the convergence of the infinite product is insured by (2.1) (see [2], p. 11). Our representation theorems will be concerned with convolution kernels of the form

$$
G(t)=(2 \pi i)^{-1} \int_{-i \infty}^{i \infty}[E(s)]^{-1} e^{s t} d s, \quad-\infty<t<\infty .
$$

Also set

$$
\begin{aligned}
& E_{m}(s)=\prod_{k=m+1}^{\infty}\left(1-\frac{s}{a_{k}}\right) e^{s / a_{k}}, \quad m \geqq 0 ; \\
& G_{m}(t)=(2 \pi i)^{-1} \int_{-i \infty}^{i \infty}\left[E_{m}(s)\right]^{-1} e^{s t} d s, \quad m \geqq 0 ; \\
& P_{n}(s)=\prod_{k=1}^{n}\left(1-\frac{s}{a_{k}}\right) e^{s / a_{k}}, \quad n \geqq 1 ;
\end{aligned}
$$


and

$$
H_{n}(t)=(2 \pi i)^{-1} \int_{-i \infty}^{i \infty}\left[P_{n}(s)\right]^{-1} e^{s t} d s, \quad n \geqq 1 .
$$

Let $D$ be differentiation with respect to $x$ and let

$$
P_{n}(D)=\prod_{k=1}^{n}\left(1-\frac{D}{a_{k}}\right) e^{D / a_{k}}, \quad n \geqq 1 .
$$

With a function $f(x)$ differentiable infinitely often in $(a, \infty)$, associate the sequence of functions defined on $(a, \infty)$ by

$$
\begin{aligned}
& f_{0}(x)=f(x) \\
& f_{n}(x)=P_{n}(D) f(x), \quad n \geqq 1 .
\end{aligned}
$$

Then a proof similar to that of [2] p. 151 (4) gives

$$
f_{n-1}(x)=-a_{n} e^{a_{n}\left(x-\left(1 / a_{n}\right)\right)} \int_{a-\left(1 / a_{n}\right)}^{x-\left(1 / a_{n}\right)} e^{-a_{n} t} f_{n}(t) d t+a_{n} C_{n} e^{a_{n}\left(x-\left(1 / a_{n}\right)\right)}
$$

where $C_{n}$ is a constant independent of $x$. Change of variable under the sign of the integral yields for all $x, u, a<x, u<\infty$,

$$
e^{-a_{n} x} f_{n-1}(x)=e^{-a_{n} u} f_{n-1}(u)+a_{n} \int_{x}^{u} e^{-a_{n} t} f_{n}\left(t-\frac{1}{a_{n}}\right) d t .
$$

Denote $\lambda_{0}=0$ and $\lambda_{n}=\sum_{k=1}^{n} 1 / a_{k}, \quad n \geqq 1$; and denote $a_{0} !=1$ and $a_{n} !=a_{1} \cdots a_{n}, n \geqq 1$. Then the following result plays a central role in the sequel.

LEMma. Let $f(x)$ be differentiable infinitely often in $(a, \infty)$ and let $a<x<u<\infty$. Then for every $n \geqq 0$,

$$
f(x)=\sum_{k=0}^{n} \frac{1}{a_{k+1}} f_{k}\left(u-\lambda_{k}\right) H_{k+1}\left(x-u+\lambda_{k+1}\right)+R_{n}(x, u),
$$

where

$$
R_{n}(x, u)=\int_{x}^{u} f_{n+1}\left(t-\lambda_{n+1}\right) H_{n+1}\left(x-t+\lambda_{n+1}\right) d t .
$$

REMARK. It should be noted that formulae (2.4) and (2.5) bear strong resemblance to Badaljan's formulae for the generalized Taylor expansion with remainder (see for example [1], (1.23) through (1.25)).

Proof of the lemma. Let $a<x<u<\infty$. Then it follows by (2.3) for $n=1$, that 


$$
\begin{aligned}
f(x) & =e^{a_{1}(x-u)} f(u)+a_{1} \int_{x}^{u} e^{a_{1}(x-t)} f_{1}\left(t-\lambda_{1}\right) d t \\
& =\frac{1}{a_{1}} f(u) H_{1}\left(x-u+\lambda_{1}\right)+R_{0}(x, u) .
\end{aligned}
$$

Now proceed by induction assuming (2.4) and (2.5) for $n \geqq 0$ and proving it for $n+1$. To this end we have by (2.3) for $n+2$ and by (2.4) and (2.5) for $n$,

$$
\begin{aligned}
f(x)= & \sum_{k=0}^{n} \frac{1}{a_{k+1}} f_{k}\left(u-\lambda_{k}\right) H_{k+1}\left(x-u+\lambda_{k+1}\right) \\
& +\int_{x}^{u} e^{a_{n+2}(t-u)} f_{n+1}\left(u-\lambda_{n+1}\right) H_{n+1}\left(x-t+\lambda_{n+1}\right) d t \\
& +\int_{x}^{u} a_{n+2} \int_{t}^{u} e^{a_{n+2}(t-v)} f_{n+2}\left(v-\lambda_{n+2}\right) d v H_{n+1}\left(x-t+\lambda_{n+1}\right) d t .
\end{aligned}
$$

Now it is well-known that

$$
\int_{x}^{u} e^{a_{n+1}(t-u)} H_{n+1}\left(x-t-\lambda_{n+1}\right) d t=\frac{1}{a_{n+2}} H_{n+2}\left(x-u+\lambda_{n+2}\right) .
$$

Also changing of the order of integration in the third term on the right-hand side of (2.6), shows that it is equal to

$$
\int_{x}^{u} f_{n+2}\left(v-\lambda_{n+2}\right) H_{n+2}\left(x-v+\lambda_{n+2}\right) d v=R_{n+1}(x, u) .
$$

This completes our proof.

3. Determining functions of bounded variation. In this section we prove the following

THEOREM 1. Necessary and sufficient conditions in order that $f(x)$ possess the representation

$$
f(x)=\int_{-\infty}^{\infty} G(x-t) d \alpha(t), \quad \gamma<x<\infty,
$$

where $\alpha(t)$ is of bounded variation in $(-\infty, \infty)$, are that $f(x)$ is differentiable infinitely often in $(\gamma, \infty)$ and that

$$
\sup _{r<x<\infty} \sum_{n=0}^{\infty} \frac{1}{a_{n+1}}\left|f_{n}\left(x-\lambda_{n}\right)\right|=H<\infty .
$$

Furthermore

$$
\int_{-\infty}^{\infty}|d \alpha(t)|=H
$$


REMARK. A kernel in Class II has usually one more parameter, a real number $b$. Also the definition of the kernels $G_{m}(t)$ and $H_{n}(t)$ involves a sequence of parameters $\left\{b_{m}\right\}$ tending to 0 as $m \rightarrow \infty$, (see [2], p. 125). We have restricted ourselves to the case $b=b_{m}=0$, $m \geqq 1$, for convenience in both the writing of the article and the use of references $[1,5]$ where this case is the only one discussed. The results of this paper can be easily extended to the general case and this is left for the reader.

A representation theorem involving integral conditions can be found in [2], p. 156, Th. 5.2 a. However, in this result the representation (3.1) is assumed to hold throughout the real line while we allow representation in a half line.

Proof of Theorem 1. First we prove sufficiency. We prove first that condition (3.2) implies that for $\gamma<x<u<\infty$,

$$
f(x)=\sum_{k=0}^{\infty} \frac{1}{a_{k+1}} f_{k}\left(u-\lambda_{k}\right) H_{k+1}\left(x-u+\lambda_{k+1}\right) .
$$

Since $H_{n}(t) \rightarrow G(t)$, uniformly in $(-\infty, \infty)$, as $n \rightarrow \infty$ (see [2], p. 152, Lemma 4.1) and since $G(t)$ is bounded in $(-\infty, \infty)$ it follows that for $n$ sufficiently large the functions $H_{n}(t)$ are uniformly bounded in $(-\infty, \infty)$. Hence the series on the righthand side of (3.3) converges. Therefore by virtue of (2.4) it suffices to prove that for some subsequence $\left\{n_{j}\right\}, R_{n_{j}}(x, u) \rightarrow 0$ as $j \rightarrow \infty$. To this end observe that by (3.2)

$$
\sum_{n=0}^{\infty} \frac{1}{a_{n+1}} \int_{x}^{u}\left|f_{n}\left(t-\lambda_{n}\right)\right| d t<\infty ;
$$

on the other hand by $(2.1)$

$$
\sum_{n=0}^{\infty} \frac{1}{a_{n+1}}=\infty .
$$

Consequently there is a subsequence $\left\{n_{j}+1\right\}$ such that

$$
\int_{x}^{u}\left|f_{n_{j}+1}\left(t-\lambda_{n_{j}+1}\right)\right| d t \rightarrow 0 \quad \text { as } \quad j \rightarrow \infty \text {. }
$$

Now by the uniform boundedness of the functions $H_{n}(t)$ for $n$ sufficiently large it follows by (2.5) and (3.4) that $R_{n_{j}}(x, u) \rightarrow 0$ as $j \rightarrow \infty$. This completes the proof of (3.3). We have already noted that $H_{n}(t) \rightarrow G(t)$, uniformly in $(-\infty, \infty)$, as $n \rightarrow \infty$. Also for each fixed $n, H_{n}(t) \rightarrow 0$ as $t \rightarrow-\infty$ and $G(t) \rightarrow 0$ as $t \rightarrow-\infty$. Hence it follows by (3.2) and (3.3) that for $\gamma<x<\infty$ 


$$
f(x)=\lim _{u \rightarrow \infty} \sum_{k=0}^{\infty} \frac{1}{a_{k+1}} f_{k}\left(u-\lambda_{k}\right) G\left(x-u+\lambda_{k+1}\right) .
$$

Define now the functions $\alpha_{u}(t)(u>\gamma)$ by

$$
\alpha_{u}(t)=\sum_{u-\lambda_{n+1} \leqq t} \frac{1}{a_{n+1}} f_{n}\left(u-\lambda_{n}\right), \quad-\infty<t<\infty .
$$

Then the functions $\alpha_{u}(t)$ are of uniformly bounded variations and (3.5) can be rewritten as

$$
f(x)=\lim _{u \rightarrow \infty} \int_{-\infty}^{\infty} G(x-t) d \alpha_{u}(t), \quad \gamma<x<\infty .
$$

By [2], p. 156, Th. 5.1 there exists a sequence $\left\{u_{j}\right\}$ and a function of bounded variation $\alpha(t)$ such that $\alpha_{u_{j}}(t) \rightarrow \alpha(t),-\infty<t<\infty$, as $j \rightarrow \infty$, and for all $\gamma<x<\infty$,

$$
f(x)=\lim _{j \rightarrow \infty} \int_{-\infty}^{\infty} G(x-t) d \alpha_{u_{j}}(t)=\int_{-\infty}^{\infty} G(x-t) d \alpha(t) .
$$

Since $G(t) \rightarrow 0$ as $t \rightarrow \pm \infty$. This completes the proof of (3.1). Also it is obvious that

$$
\int_{-\infty}^{\infty}|d \alpha(t)| \leqq H
$$

The converse follows by [1], (1.30) and [5] Th. 1, however, we will give a direct proof as we need some of the results for $\S 4$.

First it follows by (3.1) and [2], p. 129, Th. 5. 2a that $f(x)$ is differentiable infinitely often in $(\gamma, \infty)$ and that

$$
f_{n}(x)=\int_{-\infty}^{\infty} G_{n}(x-t) d \alpha(t), \quad \gamma<x<\infty .
$$

Consequently

$$
\sum_{n=0}^{\infty} \frac{1}{a_{n+1}}\left|f_{n}\left(x-\lambda_{n}\right)\right| \leqq \int_{-\infty}^{\infty} \sum_{n=0}^{\infty} \frac{1}{a_{n+1}} G_{n}\left(x-\lambda_{n}-t\right)|d \alpha(t)|
$$

and our proof will be complete when we show that for all $x, t$, $-\infty<x, t<\infty$,

$$
\sum_{n=0}^{\infty} \frac{1}{a_{n+1}} G_{n}\left(x-\lambda_{n}-t\right) \leqq 1 .
$$

Now set $a_{0}=0$ and define the functions $\Lambda_{N n}(t), 0 \leqq n \leqq N$, by

$$
\int_{-\infty}^{\infty} \Lambda_{N n}(t) e^{-s t} d t=\left[\left(a_{n}-s\right) \prod_{k=n+1}^{N}\left(1-\frac{s}{a_{k}}\right)\right]^{-1}, \operatorname{Re} s<a_{n},
$$

where for $n=N$ the right hand side is interpreted as $\left(a_{n}-s\right)^{-1}$. It 
then follows similar to [2], p. 241-242 (although some of our $a_{k}$ may not be different from one another) that

$$
\Lambda_{N n}(t)=0, \quad 0<t<\infty
$$

and

$$
\sum_{n=0}^{N} \Lambda_{N n}(t)=1, \quad-\infty<t \leqq 0
$$

Convoluting both sides of (3.11) by $G_{N}(t)$ we obtain

$$
\int_{-\infty}^{0} G\left(t+\lambda_{N}-u\right) d u+\sum_{k=0}^{N-1} \frac{1}{a_{k+1}} G_{k}\left(t+\lambda_{N}-\lambda_{k}\right)=\int_{-\infty}^{0} G_{N}(t-u) d u .
$$

Hence

$$
\int_{-\infty}^{0} G(t-u) d u+\sum_{k=0}^{N-1} \frac{1}{a_{\dot{k}+1}} G_{k}\left(t-\lambda_{k}\right) \leqq 1,
$$

and since $\int_{-\infty}^{0} G(t-u) d u \geqq 0,(3.10)$ is evident. This completes the proof of (3.2); and to conclude the proof of the theorem we observe that by (3.9) and (3.10),

$$
H \leqq \int_{-\infty}^{\infty}|d \alpha(t)|
$$

Our proof is now complete.

4. Determining functions in Orlicz classes. Let the function $M(u)$ be an even, continuous, convex function satisfying (1) $M(u) / u \rightarrow 0$ as $u \rightarrow 0,(2) M(u) / u \rightarrow \infty$ as $u \rightarrow \infty$. Let $L_{M}(-\infty, \infty)$ denote the class of measurable functions $\varphi(x)$ in $(-\infty, \infty)$ which satisfy

$$
\int_{-\infty}^{\infty} M[\varphi(x)] d x<\infty \text {. }
$$

$L_{M}(-\infty, \infty)$ is known as the Orlicz class associated with $M(u)$ and is not necessarily a linear space (see [3]). The space $L^{p}(-\infty, \infty)$, $1<p<\infty$, is obtained as the orlicz class associated with $M(u)=|u|^{p}$. First we give a necessary condition.

THEOREM 2. If $f(x)$ possesses the representation

$$
f(x)=\int_{-\infty}^{\infty} G(x-t) \varphi(t) d t, \quad \gamma<x<\infty,
$$

where $\varphi(t) \in L_{M}(-\infty, \infty)$, then $f(x)$ is differentiable infinitely often in $(\gamma, \infty)$ and 


$$
\sup _{r<x<\infty} \sum_{n=0}^{\infty} \frac{1}{a_{n+1}} M\left[f_{n}\left(x-\lambda_{n}\right)\right] \equiv H<\infty
$$

Furthermore

$$
H \leqq \int_{-\infty}^{\infty} M[\varphi(x)] d x
$$

Proof. By (4.1) and [2], p. 129, Th. 5. 2a, $f(x)$ is! differentiable infinitely often in $(\gamma, \infty)$ and

$$
f_{n}(x)=\int_{-\infty}^{\infty} G_{n}(x-t) \varphi(t) d t, \quad \gamma<x<\infty .
$$

Thus by Jensen's inequality (see [8], p. 23 (10.8))

$$
M\left[f_{n}\left(x-\lambda_{n}\right)\right] \leqq \int_{-\infty}^{\infty} G_{n}\left(x-\lambda_{n}-t\right) M[\varphi(t)] d t,
$$

since

$$
\int_{-\infty}^{\infty} G_{n}(t) d t=1, \quad n \geqq 0 .
$$

Consequently by (3.10),

$$
\begin{aligned}
\sum_{n=0}^{\infty} \frac{1}{a_{n+1}} M\left[f_{n}\left(x-\lambda_{n}\right)\right] & \leqq \int_{-\infty}^{\infty} \sum_{n=0}^{\infty} \frac{1}{a_{n+1}} G_{n}\left(x-\lambda_{n}-t\right) M[\varphi(t)] d t \\
& \leqq \int_{-\infty}^{\infty} M[\varphi(t)] d t<\infty .
\end{aligned}
$$

This proves (4.2) and also that

$$
H \leqq \int_{-\infty}^{\infty} M[\varphi(t)] d t
$$

A partial converse of Theorem 2 is the following

THEOREM 3. If $f(x)$ possesses the representation (3.1) and if (4.2) holds, then $f(x)$ possesses the representation (4.1) where $\varphi(t) \in$ $L_{M}(-\infty, \infty)$. Furthermore $\int_{-\infty}^{\infty} M[\varphi(t)] d t \leqq H$.

REMARK. Theorem 3 is not a satisfactory converse of Theorem 2 since not every function in $L_{M}(-\infty, \infty)$ is also integrable. One would conjecture that (4.2) with the fact that $f(x)$ is differentiable in $(\gamma, \infty)$ would suffice for (4.1) as is the case with the Laplace transform (see [4]).

Proof of Theorem 3. The functions $\alpha_{u}(t)$ defined in (3.6) are, 
by virtue of Theorem 1, of uniformly bounded variations. Hence, as in the proof of Theorem 1, there exists a function $\alpha(t)$ such that $\alpha_{u_{j}}(t) \rightarrow \alpha(t)-\infty<t<\infty$, as $j \rightarrow \infty$ and

$$
f(x)=\int_{-\infty}^{\infty} G(x-t) d \alpha(t), \quad \gamma<x<\infty .
$$

In order to complete our proof we show that $\alpha(t)$ is the indefinite integral of a function in $L_{M}(-\infty, \infty)$. To this end, let

$$
-\infty<t_{0}<t_{1}<\cdots<t_{n}<\infty
$$

be a fixed subdivision of $(-\infty, \infty)$. Then by Jensen's inequality (see [8], p. 24 (10.10))

$$
\begin{aligned}
M\left[\frac{\alpha_{u}\left(t_{i}\right)-\alpha_{u}\left(t_{i-1}\right)}{\sum_{t_{i-1}<u-\lambda_{n+1} \leqq t_{i}} \frac{1}{a_{n+1}}}\right] & =M\left[\frac{\sum_{t_{i-1}<u-\lambda_{n+1} \leqq t_{i}} \frac{1}{a_{n+1}} f_{n}\left(u-\lambda_{n}\right)}{\sum_{t_{i-1}<u-\lambda_{n+1} \leqq t_{i}} \frac{1}{a_{n+1}}}\right] \\
& \leqq \frac{\sum_{t_{i-1}<u-\lambda_{n+1} \leqq t_{i}} \frac{1}{a_{n+1}} M\left[f_{n}\left(u-\lambda_{n}\right)\right]}{\sum_{t_{i-1}<u-\lambda_{n+1} \leqq t_{i}} \frac{1}{a_{n+1}}} .
\end{aligned}
$$

Hence by (4.2)

$$
\begin{aligned}
& \sum_{i=1}^{n}\left[\sum_{t_{i-1}<u-\lambda_{n+1} \leqq t_{i}} \frac{1}{a_{n+1}}\right] M\left[\frac{\alpha_{u}\left(t_{i}\right)-\alpha_{u}\left(t_{i-1}\right)}{\sum_{t_{i-1}<u-\lambda_{n+1} t_{i}} \frac{1}{a_{n+1}}}\right] \\
\leqq & \sum_{n=0}^{\infty} \frac{1}{a_{n+1}} M\left[f_{n}\left(u-\lambda_{n}\right)\right] \leqq H<\infty .
\end{aligned}
$$

Now $\lim _{j \rightarrow \infty}\left\{\alpha_{u_{j}}\left(t_{i}\right)-\alpha_{u_{j}}\left(t_{i-1}\right)\right\}=\alpha\left(t_{i}\right)-\alpha\left(t_{i-1}\right)$ and, as is readily seen,

$$
\lim _{u \rightarrow \infty} \sum_{t_{i-1}<u-\lambda_{n+1} \leqq t_{i}} \frac{1}{a_{n+1}}=t_{i}-t_{i-1} .
$$

So (4.4) implies

$$
\sum_{i=1}^{n}\left(t_{i}-t_{i-1}\right) M\left[\frac{\alpha\left(t_{i}\right)-\alpha\left(t_{i-1}\right)}{t_{i}-t_{i-1}}\right] \leqq H .
$$

Since (4.5) holds for any finite subdivision of $(-\infty, \infty)$ it follows by a slight modification of Medvedev's theorem [6] that

$$
\alpha(t)=c+\int_{0}^{t} \varphi(v) d v, \quad-\infty<t<\infty,
$$

where $\varphi(v) \in L_{M}(-\infty, \infty)$. This in turn implies, together with (4.3), that $f(x)$ has the representation (4.1). Also 


$$
\int_{-\infty}^{\infty} M[\varphi(t)] d t \leqq H
$$

This completes our proof.

\section{REFERENCES}

1. G. V. Badaljan, The application of a convolution transform to the theory of the generalized Stieltjes moment problem, Math. USSR Izv. 1 (1967), 475-514; English trans. of Izv. Akad. Nauk. SSSR Ser. Mat. 31 (1967), 491-530.

2. I. I. Hirschman and D. V. Widder, The Convolution Transform, Princeton Univ. Press, 1955.

3. M. A. Krasnoselskii and Ya. B. Rutickii, Convex Function and Orlicz Spaces, trans. by Leo F. Boron, P. Noordhoff Ltd. Groningen, The Netherlands, 1961.

4. D. Leviatan, On the representation of functions as Laplace integrals, J. London Math. Soc. 44 (1969) 88-92.

5. - An application of a convolution transform to the sequence-to-function analogues of Hausdorff transformations, J. d'Analyse Math. (to appear)

6. Yu. Medvedev, Generalization of a theorem of $F$. Riesz, Uspehi Mat. Nauk. 8 (1953), 115-118.

7. D. V. Widder, The Lapalce Transform, Princeton Univ. Press, 1946.

8. A. Zygmund, Trigonometric Series I, second edition, Cambridge Univ. Press.

Received August 7, 1969.

UNIVERSITY OF ILLINOIS

URBANA, ILLINOIS

AND

TEL-AVIV UNIVERSITY

ISRAEL 



\section{PACIFIC JOURNAL OF MATHEMATICS}

\section{EDITORS}

\author{
H. SAMELSON \\ Stanford University \\ Stanford, California 94305

\section{Richard Pierce} \\ University of Washington \\ Seattle, Washington 98105
}

J. DugundJI

Department of Mathematics

University of Southern California

Los Angeles, California 90007

RichaRd ARENS

University of California

Los Angeles, California 90024

\section{ASSOCIATE EDITORS}
E. F. BECKENBACH
B. H. NeUMANN
F. WOLE
K. YoshidA

\section{SUPPORTING INSTITUTIONS}

\author{
UNIVERSITY OF BRITISH COLUMBIA \\ CALIFORNIA INSTITUTE OF TECHNOLOGY \\ UNIVERSITY OF CALIFORNIA \\ MONTANA STATE UNIVERSITY \\ UNIVERSITY OF NEVADA \\ NEW MEXICO STATE UNIVERSITY \\ OREGON STATE UNIVERSITY \\ UNIVERSITY OF OREGON \\ OSAKA UNIVERSITY \\ UNIVERSITY OF SOUTHERN CALIFORNIA
}

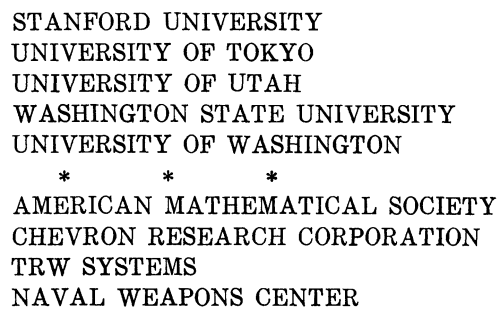

The Supporting Institutions listed above contribute to the cost of publication of this Journal, but they are not owners or publishers and have no responsibility for its content or policies.

Mathematical papers intended for publication in the Pacific Journal of Mathematics should be in typed form or offset-reproduced, (not dittoed), double spaced with large margins. Underline Greek letters in red, German in green, and script in blue. The first paragraph or two must be capable of being used separately as a synopsis of the entire paper. The editorial "we" must not be used in the synopsis, and items of the bibliography should not be cited there unless absolutely necessary, in which case they must be identified by author and Journal, rather than by item number. Manuscripts, in duplicate if possible, may be sent to any one of the four editors. Please classify according to the scheme of Math. Rev. Index to Vol. 39. All other communications to the editors should be addressed to the managing editor, Richard Arens, University of California, Los Angeles, California, 90024.

50 reprints are provided free for each article; additional copies may be obtained at cost in multiples of 50 .

The Pacific Journal of Mathematics is published monthly. Effective with Volume 16 the price per volume (3 numbers) is $\$ 8.00$; single issues, $\$ 3.00$. Special price for current issues to individual faculty members of supporting institutions and to individual members of the American Mathematical Society: $\$ 4.00$ per volume; single issues $\$ 1.50$. Back numbers are available.

Subscriptions, orders for back numbers, and changes of address should be sent to Pacific Journal of Mathematics, 103 Highland Boulevard, Berkeley, California, 94708.

PUBLISHED BY PACIFIC JOURNAL OF MATHEMATICS, A NON-PROFIT CORPORATION

Printed at Kokusai Bunken Insatsusha (International Academic Printing Co., Ltd.), 7-17, Fuj̣imi 2-chome, Chiyoda-ku, Tokyo, Japan. 


\section{Pacific Journal of Mathematics}

\section{Vol. 35, No. $2 \quad$ October, 1970}

Valentin Danilovich Belousov and Palaniappan L. Kannappan, Generalized Bol functional equation .................................... 259

Charles Morgan Biles, Gelfand and Wallman-type compactifications ........... 267

Louis Harvey Blake, A generalization of martingales and two consequent convergence theorems .................................... 279

Dennis K. Burke, On p-spaces and $w \Delta$-spaces..................... 285

John Ben Butler, Jr., Almost smooth perturbations of self-adjoint operators . . . . . . 297

Michael James Cambern, Isomorphisms of $C_{0}(Y)$ onto $C(X) \ldots \ldots \ldots \ldots \ldots . \ldots 307$

David Edwin Cook, A conditionally compact point set with noncompact closure ... 313

Timothy Edwin Cramer, Countable Boolean algebras as subalgebras and homomorphs .........................................

John R. Edwards and Stanley G. Wayment, A v-integral representation for linear operators on spaces of continuous functions with values in topological vector spaces.............................................

Mary Rodriguez Embry, Similarities involving normal operators on Hilbert

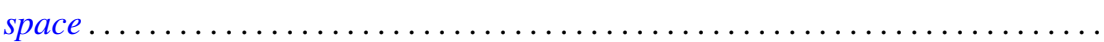

Lynn Harry Erbe, Oscillation theorems for second order linear differential

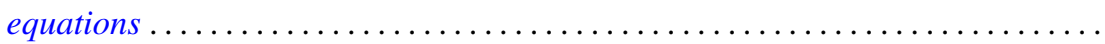

William James Firey, Local behaviour of area functions of convex bodies .......... Joe Wayne Fisher, The primary decomposition theory for modules ..............

Gerald Seymour Garfinkel, Generic splitting algebras for Pic ..................

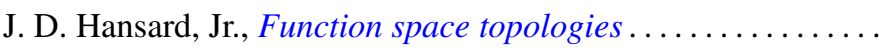

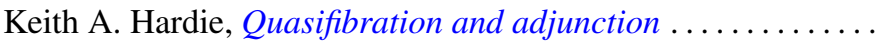

G. Hochschild, Coverings of pro-affine algebraic groups ...........

Gerald L. Itzkowitz, On nets of contractive maps in uniform spaces ..

381

389

399

417

Melven Robert Krom and Myren Laurance Krom, Groups with free nonabelian subgroups....................................

James Robert Kuttler, Upper and lower bounds for eigenvalues by finite differences ......................................

Dany Leviatan, A new approach to representation theory for convolution transforms . . .

Richard Beech Mansfield, Perfect subsets of definable sets of real numbers ...

Brenda MacGibbon, A necessary and sufficient condition for the embedding of a

Lindelof space in a Hausdorff $\mathscr{H} \sigma$ space ..................

David G. Mead and B. D. McLemore, Ritt's question on the Wronskian ....

Edward Yoshio Mikami, Focal points in a control problem .....

Paul G. Miller, Characterizing the distributions of three independent n-dimensional random variables, $X_{1}, X_{2}, X_{3}$, having analytic characteristic functions by the joint distribution of $\left(X_{1}+X_{3}, X_{2}+X_{3}\right)$. . .

P. Rosenthal, On the Bergman integral operator for an elliptic partial differential equation with a singular coefficient....

Douglas B. Smith, On the number of finitely generated $O$-group 